\title{
Article \\ Color Analysis of Metal Ceramic Restorations Fabricated from Different Dental Laboratories
}

\author{
Abdullah Saleh Aljamhan ${ }^{1}\left(\mathbb{D}\right.$, Syed Rashid Habib ${ }^{2, *}{ }^{\mathbb{C}}$, Aleshba Saba Khan ${ }^{3}{ }^{(}$, Muhammad Qasim Javed ${ }^{4} \mathbb{D}^{\circ}$, \\ Usman Anwer Bhatti ${ }^{5}$ and Muhammad Sohail Zafar ${ }^{6,7}$ (D)
}

1 Restorative Dental Sciences Department, College of Dentistry, King Saud University, Riyadh 11545, Saudi Arabia; a.aljamhan@ksu.edu.sa

2 Department of Prosthetic Dental Sciences, College of Dentistry, King Saud University, Riyadh 11545, Saudi Arabia

3 Department of Prosthodontics, Shahida Islam Dental College, Lodhran 59320, Pakistan; aleshba.saba@hotmail.com

4 Department of Conservative Dental Sciences, College of Dentistry, Qassim University, Qassim 52571, Saudi Arabia; m.anayat@qu.edu.sa

5 Department of Operative Dentistry, Riphah International University, Islamabad 44000, Pakistan; usman.anwer@riphah.edu.pk

6 Department of Restorative Dentistry, College of Dentistry, Taibah University, Al Madinah, Al Munawwarah 41311, Saudi Arabia; mzafar@taibahu.edu.sa

7 Department of Dental Materials, Islamic International Dental College, Riphah International University, Islamabad 44000, Pakistan

* Correspondence: syhabib@ksu.edu.sa; Tel.: +966-53475-0834

check for

updates

Citation: Aljamhan, A.S.; Habib, S.R.; Khan, A.S.; Javed, M.Q.; Bhatti, U.A.; Zafar, M.S. Color Analysis of Metal Ceramic Restorations Fabricated from Different Dental Laboratories. Coatings 2022, 12, 297. https:// doi.org/10.3390/coatings12030297

Academic Editors: Monika Lukomska-Szymanska and Devis Bellucci

Received: 17 December 2021 Accepted: 19 February 2022 Published: 22 February 2022

Publisher's Note: MDPI stays neutral with regard to jurisdictional claims in published maps and institutional affiliations.

Copyright: (C) 2022 by the authors. Licensee MDPI, Basel, Switzerland. This article is an open access article distributed under the terms and conditions of the Creative Commons Attribution (CC BY) license (https:// creativecommons.org/licenses/by/ $4.0 /)$.

\begin{abstract}
Objective: The aim of the present in vitro study was to explore the differences in color matching of most frequently used shades for metal ceramic dental restorations fabricated by different laboratories. Materials and Methods: A total sample size of 180 discs of metal ceramic were prepared by six laboratories (labs): each lab prepared 30 samples, 10 for each shade (A1, B1, and C1). Instructions for standardization were provided. A spectrophotometer and CIE LAB system was used to find $\triangle \mathrm{E}$ value for difference between shades observed by spectrophotometer. For statistical analysis, ANOVA and post hoc Tukey tests were used. Significance level was $<0.05$. Results: Significant variation $(p=0.000)$ was observed among the labs for $\Delta \mathrm{E}$. The maximum value for $\Delta \mathrm{E}$ in shade $\mathrm{A} 1$ was $77.0 \pm 0.065$ and minimum value for $\Delta \mathrm{E}$ noted for shade $\mathrm{A} 1$ was $69.19 \pm 1.39$. The values of $\Delta \mathrm{E}$ for shade B1 were maximum $80.14 \pm 0.16$ and minimum $68.38 \pm 0.40$ and the values of $\Delta \mathrm{E}$ for shade $\mathrm{C} 1$ were maximum $80.16 \pm 0.14$ and minimum $71.62 \pm 1.23$. Twelve out of 15 comparisons between labs for shade A1, 14 of 15 comparisons for shade B1, and 11 of 15 comparisons for shade $\mathrm{C} 1$ showed significant difference $(p=0.000)$. Conclusions: Similar tooth shades (A1, B1, and C1) when duplicated by different labs exhibited highly significant color variations.
\end{abstract}

Keywords: dental shade; metal ceramic restorations; color difference; spectrophotometer; delta e; tooth shade

\section{Introduction}

One of the most significant factors for success of any fixed dental prosthetic restoration is the accuracy of shade matching with the surrounding dentition [1]. The importance of accurate color matching is further increased when restoring anterior teeth [2]. Metal ceramic restorations are widely used because they provide composite of both strength and esthetic [2,3]. Multiple features of restorations such as shade, shape, and texture play an instrumental role in giving a natural appearance [4]. Duplicating the exact shade of that of surrounding teeth is more challenging in the case of metal ceramic restorations due to the dark-colored metal underlying the translucent porcelain [2,5-7]. Factors other than the underlying metal that make the color matching more demanding include adequate tooth preparation, proper selection of appropriate shade in clinics, different brands 
of porcelain requiring variation in condensation techniques, translucency, fluorescence, opacity, thickness of porcelain layer, surface characteristics, time, and temperature of firing porcelain $[2,4,5,7]$.

To attain best possible esthetics, the duplication of shades of porcelain is performed in two phases, shade selection followed by shade duplication [4]. The first step is performed in the clinic and the second is a challenge for the laboratory (lab) $[4,5]$. In dental clinics, the shade selection is dependent on multiple factors such as observer, light source, surroundings such as makeup, color of walls, gloves, cleanliness of teeth, duration and time of shade selection, distance from teeth, and level of eyes of observer when noting the shade [8]. The techniques for color matching are broadly categorized into instrumental or visual analysis [3,9]. Many methods are available for shade assessment such as objective analysis by spectrophotometer, three-dimensional guide, digital shade scanner, image analysis technique, and colorimeter $[4,8]$. Presently, the use of digital cameras for noting the shade and communicating it to the lab is also being practiced [4]. After ensuring the accuracy of clinical technique for shade matching, effective and clear communication between clinic and laboratory personnel also plays an influential role in accurate shade duplication [9].

The precision in color matching or reproduction in the final product may vary from natural teeth or even shade tab due to various reasons in the laboratory [4]. The actual cause of the variation in color is still undetermined [2]. The possible reason for variations in shades may be associated with various factors: optical changes and thickness of opaque layer after firing of porcelain, effect of metal oxides, different type of metal copings used underneath porcelain, and skills of the technician [2,10]. The change in color may also be due to use of shade guide of different brand from the brand of porcelain used in the laboratory $[4,10]$. In addition, changes in the surface texture due to glazing, the technique sensitivity, variability, and complexity in procedures to fabricate a restoration further add to the risk factors of increasing errors [6].

With recent advances in prosthodontics regarding techniques, materials and technology, shade matching, and reproduction has been improvised [4,10]. The CIE LAB system aids in detailed measurement of shade as well as helps in recognizing any difference in value, chroma, or hue of the shade [2,4]. Still, there is room for improvement in replication of accurate shade of restoration and further evaluation of factors leading to the difference in shades when restorations are fabricated in different laboratories. This knowledge needs the realization that different shade production from color matching appointment is still an issue and needs to be addressed. Even though the dental professionals have been mindful of the fact that there are variations between shade tab and shade reproduced on the restorations since long ago, recently the need to improve this issue has been arising due to more awareness through media about esthetics and pressure to improve appearance or smile as well as the improving standard of the dental specialists and higher expectations from the patients $[3,10]$. Objective measurement of shade using the instrumental methods is considered more accurate compared to subjective analysis of shade [8]. Spectrophotometry and the CIE LAB system aid in objective evaluation of the shade [8]. Thus, the present study utilized a spectrophotometer for evaluation of shade with the aim to analyze the differences in color of metal ceramic restorations fabricated from different laboratories.

\section{Materials and Methods}

The research was carried out at the Department of Prosthodontics and CDRC, College of Dentistry, King Saud University, Riyadh, KSA.

\subsection{Calculation of Sample Size for Each Shade and Total Sample Size}

Six different laboratories were requested to prepare the samples of metal ceramic discs, ten samples of shade A1, ten of shade B1, and ten of shade C1. Each laboratory provided 30 samples, and total samples from all labs were $180(\mathrm{~N}=180)$. For the power analysis of the sample size, G-power software ( $\mathrm{G}^{*}$ Power 3.1.9.7, Germany) was used, keeping in view the sample sizes used in some of the previously reported research. The total sample 
size calculated was to be 180 specimens; 30 specimens each for the six dental laboratories included in the study. The analysis was carried out with the effect size (0.5), power (0.82), and the level of significance $(p<0.05)$.

\subsection{Sample Fabrication}

The samples for test groups were prepared in the shape of discs with standard dimensions of $2 \mathrm{~mm}$ thickness and $10 \mathrm{~mm}$ diameter, as described previously [2]. No special instructions were given to the dental laboratories for using a specific brand of metal ceramic material. However, the dental laboratories were instructed to follow the manufacturers' recommendations for fabrication of the specimens. The sequence used for fabrication of discs involved fabrication of the metal part of the disc followed by porcelain powder application over the metal in three phases, i.e., wash opaque, followed by opaque, and lastly build up porcelain. The specimens were prepared by skilled technicians and two specialists assessed the prepared metal ceramic discs (Figure 1). Thickness was standardized and confirmed by using an electronic caliper device [2].
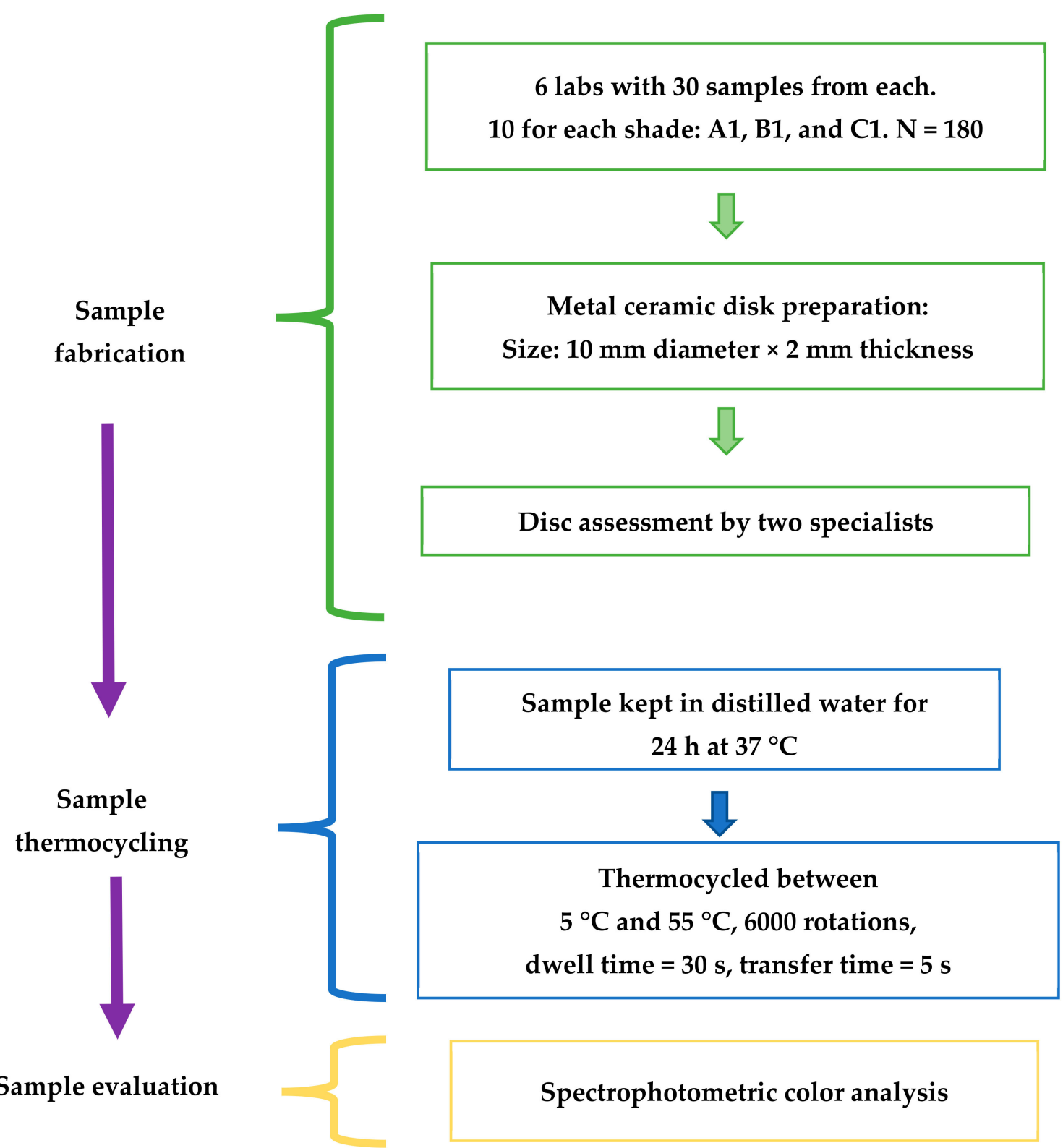

Figure 1. Flow chart for study methodology. 


\subsection{Thermocycling of Samples}

To imitate the clinical condition or condition in oral cavity, the prepared samples were kept in distilled water at temperature of $37^{\circ} \mathrm{C}$ for $24 \mathrm{~h}$. Samples were then subjected to process of ageing by keeping the sample in a thermocycling machine (Huber, SDMechatronik-Thermocycler, Westerham, Germany) between temperatures $5{ }^{\circ} \mathrm{C}$ and $55^{\circ} \mathrm{C}$ for 6000 rotations with a $30 \mathrm{~s}$ dwell time and a $5 \mathrm{~s}$ transfer time [11].

\subsection{Color Analysis of Samples}

A spectrophotometer (LabScan-XE ${ }^{\circledR}$, Hunter-Lab, Sunset Hills Road, Reston, VA, USA) was used for measurements of color coordinates of all the test samples. This device is considered to be a reliable tool for determining the tooth shade and is considered the gold standard for the research studies related to tooth color [9-11]. Each prepared sample was positioned over the spectrophotometer sensor, and three observations for every sample were noted. The instrument sent light waves into the test specimens and the light waves either refracted or reflected back to the receiver were quantified as $\mathrm{L}^{*} \mathrm{a}^{*} \mathrm{~b}^{*}$ color coordinates based on the opponent color theory assuming that receptors in the human eye perceive color as the following pairs of opposites. The " $\mathrm{L}$ " value for each scale indicated the level of light/dark, the "a" value redness/greenness, and the " $b$ " value yellowness/blueness. All three values were obtained for complete description of the specimen's color. Stability of color was evaluated by calculating delta $\mathrm{E}(\Delta \mathrm{E})$ using $\mathrm{L}^{*} \mathrm{a}^{*} \mathrm{~b}^{*}$ values using the below mentioned formula [9-11]:

$$
\Delta \mathrm{E}=\left[\left(\Delta \mathrm{L}^{*}\right) 2+\left(\Delta \mathrm{a}^{*}\right) 2+\left(\Delta \mathrm{b}^{*}\right) 2\right]^{1 / 2}
$$

\subsection{Statistical Analysis}

All the data was compiled and analyzed using Statistical Package for Social Sciences (SPSS; Version 23; SPSS Inc., Chicago, IL, USA). The mean values of $\mathrm{L}^{*} \mathrm{a}^{*} \mathrm{~b}^{*}$ color coordinates, calculation of $\Delta \mathrm{E}$ from the $\mathrm{L}^{*} \mathrm{a}^{*} \mathrm{~b}^{*}$ values for each sample of the metal ceramic disks, were included in descriptive variables. The data were found to be normally distributed according to Kolmogorov-Smirnov test. The statistical analysis included comparisons of $\Delta \mathrm{E}$ mean values with confidence interval of $95 \%$ for all samples from all labs using one-way analysis of variance (ANOVA) and Tukey's post hoc tests for multiple comparisons. The level of significance was set at $\alpha<0.05$.

\section{Results}

A total sample of $\mathrm{N}=180$ porcelain fused to metal discs were collected from six labs. Each lab provided 10 samples (30 from each lab) for each shade, i.e., A1, B1, and C1. Each shade contributed equally $(33.33 \% ; 60 / 180)$ to the sample size.

- Descriptive statistics for shade $\left(L^{*} a^{*} b^{*}\right)$ :

Statistics for descriptive variables (standard deviation (S.D.) and mean) of values for $\mathrm{L}^{*} \mathrm{a}^{*} \mathrm{~b}^{*}$ were noted with the help of the spectrophotometer for all the samples $(\mathrm{N}=180)$ as presented in Tables 1-3. The minimum value for $L^{*}$ (lightness) was $67.98 \pm 1.32$ in shade A1 (lab 1), and maximum value for $L^{*}$ was $79.85 \pm 0.12$ in shade $C 1$ (lab 2). The value for $\mathrm{a}^{*}$ (redness-greenness) was minimum $-2.2 \pm 0.09$ and maximum $1.19 \pm 0.27$ in shade B1 (lab 5) and A1 (lab 1), respectively. The value for $\mathrm{b}^{*}$ (yellowness and blueness) was minimum $4.75 \pm 0.18$ and maximum $14.75 \pm 0.51$ in shade B1 (lab 1) and C1 (lab 4), respectively, as shown in Tables 1-3.

\section{- Color Change:}

The delta E calculated for each shade is also shown in Tables 1-3. The P value for all shades was 0.000 , which was highly significant. This validates that there is a difference between the similar shades when obtained by different labs. The maximum value for $\Delta \mathrm{E}$ in shade $\mathrm{A} 1$ was $77.0 \pm 0.065$ by lab 5 and minimum value for $\Delta \mathrm{E}$ noted for shade $\mathrm{A} 1$ was $69.19 \pm 1.39$ by lab 1 . The values of $\Delta \mathrm{E}$ for shade $\mathrm{B} 1$ were maximum $80.14 \pm 0.16$ for lab 5 
and minimum $68.38 \pm 0.40$ for lab 1 , and the values of $\Delta \mathrm{E}$ for shade $\mathrm{C} 1$ were maximum $80.16 \pm 0.14$ by lab 2 and minimum $71.62 \pm 1.23$ by lab 4 , respectively.

Table 1. Mean values, standard deviations, and ANOVA results of the color coordinates for shade A1.

\begin{tabular}{|c|c|c|c|c|c|c|c|}
\hline \multirow{2}{*}{$\begin{array}{c}\text { Color } \\
\text { Coordinates }\end{array}$} & \multicolumn{6}{|c|}{ Dental Laboratories Included in the Study } & \multirow{2}{*}{$\begin{array}{c}\text { ANOVA } \\
p \text {-Value }\end{array}$} \\
\hline & * Lab 1 & Lab 2 & Lab 3 & Lab 4 & Lab 5 & Lab 6 & \\
\hline$\Delta \mathrm{L}$ & $67.98(1.32)$ & $75.91(0.78)$ & $72.60(0.60)$ & $68.45(1.15)$ & $76.05(0.61)$ & $72.79(0.42)$ & $0.000^{\mathrm{a}}$ \\
\hline$\Delta \mathrm{a}$ & $1.19(0.27)$ & $-0.45(0.16)$ & $0.38(0.46)$ & $1.17(0.20)$ & $-0.49(0.12)$ & $0.53(0.34)$ & $0.000^{\mathrm{a}}$ \\
\hline$\Delta \mathrm{b}$ & $12.85(0.60)$ & $11.98(0.36)$ & $14.17(0.96)$ & $12.83(0.61)$ & $12.03(0.32)$ & $14.32(0.87)$ & $0.000^{\mathrm{a}}$ \\
\hline$\Delta \mathrm{E}$ & $69.19(1.39)$ & $76.85(0.82)$ & $73.98(0.71)$ & $69.65(1.21)$ & $77.00(0.65)$ & $74.19(0.54)$ & $0.000^{\mathrm{a}}$ \\
\hline
\end{tabular}

Table 2. Mean values, standard deviations, and ANOVA results of the color coordinates for shade B1.

\begin{tabular}{cccccccc}
\hline $\begin{array}{c}\text { Color } \\
\text { Coordinates }\end{array}$ & ${ }^{*}$ Lab 1 & Lab 2 & Lab 3 & Lab 4 & Lab 5 & \multicolumn{2}{c}{ ANOVA } \\
\hline$\Delta \mathrm{L}$ & $68.21(0.39)$ & $77.42(0.56)$ & $73.79(0.73)$ & $70.75(1.14)$ & $79.83(0.15)$ & $70.69(0.55)$ & $0.000^{\mathrm{a}}$ \\
$\mathrm{Aa}$ & $-1.24(0.10)$ & $-0.56(0.14)$ & $0.50(0.30)$ & $-1.36(0.07)$ & $-2.22(0.09)$ & $-1.06(0.29)$ & $0.000^{\mathrm{a}}$ \\
$\Delta \mathrm{b}$ & $4.75(0.18)$ & $11.88(0.69)$ & $14.55(0.69)$ & $5.45(0.82)$ & $6.65(0.38)$ & $9.22(0.84)$ & $0.000^{\mathrm{a}}$ \\
$\Delta \mathrm{E}$ & $68.38(0.40)$ & $78.33(0.62)$ & $75.21(0.71)$ & $70.98(1.17)$ & $80.14(0.16)$ & $71.30(0.63)$ & $0.000^{\mathrm{a}}$ \\
\hline
\end{tabular}

${ }^{*}$ Lab = laboratory; ${ }^{\text {a }}$ ANOVA $p$-value was significant at $p<0.05$.

Table 3. Mean values, standard deviations, and ANOVA results of the color coordinates for shade C1.

\begin{tabular}{|c|c|c|c|c|c|c|c|}
\hline \multirow{2}{*}{$\begin{array}{c}\text { Color } \\
\text { Coordinates }\end{array}$} & \multicolumn{6}{|c|}{ Dental Laboratories Included in the Study } & \multirow{2}{*}{$\begin{array}{l}\text { ANOVA } \\
p \text {-Value }\end{array}$} \\
\hline & * Lab 1 & Lab 2 & Lab 3 & Lab 4 & Lab 5 & Lab 6 & \\
\hline$\Delta \mathrm{L}$ & $72.25(1.07)$ & $79.85(0.12)$ & $71.32(0.65)$ & $70.08(1.18)$ & $77.91(0.78)$ & $74.50(0.61)$ & $0.000^{\mathrm{a}}$ \\
\hline$\Delta \mathrm{a}$ & $-1.36(0.07)$ & $-2.16(0.09)$ & $-0.75(0.20)$ & $1.04(0.22)$ & $-0.44(0.17)$ & $0.34(0.57)$ & $0.000^{\mathrm{a}}$ \\
\hline$\Delta \mathrm{b}$ & $6.16(0.72)$ & $6.69(0.32)$ & $9.97(0.58)$ & $14.75(0.51)$ & $13.95(0.70)$ & $14.47(1.11)$ & $0.000^{\mathrm{a}}$ \\
\hline$\Delta \mathrm{E}$ & $72.53(1.08)$ & $80.16(0.14)$ & $72.02(0.68)$ & $71.62(1.23)$ & $79.16(0.84)$ & $75.90(0.66)$ & $0.000^{\mathrm{a}}$ \\
\hline
\end{tabular}

The multiple comparisons of $\Delta \mathrm{E}$ as analyzed by post hoc Tukey HSD test are presented in Table 4. Majority values showed statistically significant results. The mean variation between delta E values for shade A1 among different labs showed statistically significant difference in comparison between all labs except between labs 1 and 4, labs 2 and 5, and labs 3 and 6 . The mean variation between delta E values for shade B1 among different labs showed statistically significant difference in comparison between all labs except between lab 4 and 6, and for shade $C$, all values were significant except the comparison between lab 1 with 3 and 4, lab 2 with 5, and lab 3 with 4, respectively, as shown in Table 4 . Twelve out of 15 comparisons for shade A1, 14 out of 15 comparisons for shade B1, and 11 out of 15 comparisons for shade $\mathrm{C} 1$ showed significant difference in shade matching. Thus, different labs showed variations in shade reproduction. 
Table 4. Mean differences between the delta E of the tested laboratories by post hoc Tukey HSD tests.

\begin{tabular}{|c|c|c|c|c|c|c|}
\hline Shades & & * Lab 1 & Lab 2 & Lab 3 & Lab 4 & Lab 5 \\
\hline \multirow{6}{*}{ A1 } & Lab 2 & $-7.66^{a}$ & - & & & \\
\hline & Lab 3 & $-4.78^{a}$ & $2.87^{\mathrm{a}}$ & - & & \\
\hline & Lab 4 & -0.463 & $7.19^{a}$ & $4.32^{\mathrm{a}}$ & - & \\
\hline & Lab 5 & $-7.80^{\mathrm{a}}$ & -0.14 & $-3.02^{\mathrm{a}}$ & $-7.34^{\mathrm{a}}$ & - \\
\hline & Lab 6 & $-4.99^{a}$ & $2.66^{\mathrm{a}}$ & -0.21 & $-4.53^{\mathrm{a}}$ & $2.81^{\mathrm{a}}$ \\
\hline & Lab 2 & $-9.94^{\mathrm{a}}$ & - & & & \\
\hline \multirow{4}{*}{ B1 } & Lab 3 & $-6.82^{\mathrm{a}}$ & $3.11^{\mathrm{a}}$ & - & & \\
\hline & Lab 4 & $-2.59^{a}$ & $7.35^{\mathrm{a}}$ & $4.23^{\mathrm{a}}$ & - & \\
\hline & Lab 5 & $-11.75^{\mathrm{a}}$ & $-1.81^{a}$ & $-4.92^{\mathrm{a}}$ & $-9.16^{\mathrm{a}}$ & - \\
\hline & Lab 6 & $-2.91^{\mathrm{a}}$ & $7.02^{\mathrm{a}}$ & $3.91^{\mathrm{a}}$ & -0.32 & $8.83^{a}$ \\
\hline \multirow{5}{*}{$\mathrm{C} 1$} & Lab 2 & $-7.62^{\mathrm{a}}$ & - & & & \\
\hline & Lab 3 & 0.50 & $8.13^{a}$ & - & & \\
\hline & Lab 4 & 0.90 & $8.53^{a}$ & 0.40 & - & \\
\hline & Lab 5 & $-6.62^{\mathrm{a}}$ & 1.00 & $-7.13^{\mathrm{a}}$ & $-7.53^{\mathrm{a}}$ & - \\
\hline & Lab 6 & $-3.37^{\mathrm{a}}$ & $4.25^{\mathrm{a}}$ & $-3.88^{a}$ & $-4.28^{\mathrm{a}}$ & $3.25^{\mathrm{a}}$ \\
\hline
\end{tabular}

\section{Discussion}

The present study conducted the in vitro analysis of shades of metal ceramic restoration samples prepared by different laboratories. The difference in shade of samples made by different labs was estimated using a digital spectrophotometer and CIE LAB system. The objective analysis of color of metal ceramic restoration by spectrophotometer is not influenced by variations in light source or observer $[8,12,13]$. The reliability and repeatability of this technique is universally accepted as it aids in precise measurement of color of restoration [13-16]. It evaluates the absorption of light at different wavelengths [13-15]. The technique sensitivity and expensive armamentarium of the spectrophotometer limits its frequent use in clinical settings [14]. Ideally, the shade duplication from all labs should exhibit no color differences and must be standardized. Multiple factors lead to variations in color replication [1]. The slight difference in color replication of the same shade by different labs can be explained as an overlapping area between black and white, i.e., grey zone [1] Thus, exact shade match should be given a range or minor margin of error instead of a definite value [1].

The current study reported statistically significant difference in the same shades produced by different labs. This dismisses the null hypothesis of no variation in color duplication by different labs. The results of this study are in accordance with another study by Omar et al., who reported a significant difference in porcelain fused to metal crown shades when evaluated by a spectrophotometer [17]. The present study also has similar results to the research by Douglas et al., where a significant difference was observed in the shade duplication among different labs [1]. The similarity in these studies may be due to use of the same technique for evaluation in terms of objective methods of color analysis. The study provided detailed instructions for standardization at each step, thus reducing the chance of error [1].

A study by Sam et al. found a significant difference in $a^{*}$ values but the difference was insignificant in $L^{*}$ and $b^{*}$ values [7]. They finally concluded that although insignificant for some values and significant for $\mathrm{a}^{*}$, the variation was observed in all values [7]. This might be due to the differences in the sample size, as Sam et al. used only 40 crowns for observation. In addition, the mode of analysis of shade was digital pictures and visual methods [7]. This can be the reason for difference in significance of results. In addition, different parts of crown emit different wavelengths leading to variations in the optical conditions [15]. This, in addition to different lighting conditions while taking digital photographs, might have led to differences in the results.

The findings of the current study are partially in contrast to research by Bin-Shuwaish et al., who reported that shade matching was good for cervical and middle third [4]. 
Although this study also found that there was a difference in shade duplication in incisal third, this is in conformity with the present study [4]. The partial difference might be due to smaller sample size of this study, and the partial similarity of this study might be due to the use of instrumental techniques to assess shade matching or use of appropriate aperture size of the colorimeter to reduce the chances of error due to edge loss [4]. The other reasons for differences in results of different studies may be attributed to factors such as technique sensitivity of porcelain application, changes due to different number of firing cycles, glazing, thickness of porcelain in crowns, or use of different modes for assessment of shade, i.e., objective versus subjective analysis $[12,18,19]$. The differences or similarities may also be due to use of different or similar brands of porcelain or difference in equipment owned by different labs [4]. The variations may also be due to observation of different areas of curved crown as compared to analysis of flat surfaces of discs, as in the case of the present study [18,20]. According to the literature, the color changes in dental materials have been divided into three categories [17]. The $\Delta \mathrm{E}$ values greater than 3.7 depict a very poor shade match, and $\Delta E$ value of more than 2 depicts clinically unacceptable color match. The $\Delta \mathrm{E}$ value of less than 1 means that color difference is not perceptible with eyes $[6,17,21-23]$. Even though the results of the present study demonstrated significant findings for shade variation, the values fall under the third category, which means that color difference is not evident to unaided sight; thus, slight variation is acceptable clinically.

Although great effort was made to ensure standardization, some limitations are still unavoidable. There is always a margin for human error in preparation of samples or observation of reading [4]. Other limitations of the study were that single porcelain brand was not specified to be used by all labs, which might have resulted in difference of shades due to difference in brands. Disc-shaped samples should have been compared with discs, or proper crowns should have been formed for more accurate analysis. Since this was in vitro analysis, the sample observed was dry, whereas for in vivo, the crown surface is wet. For future studies, it is recommended to include, assess, and compare parameters related to the materials, processing technologies, and surface finishing/glazing. Furthermore, using a thin layer of saliva or salivary simulant when performing in vitro analysis will be valuable.

\section{Conclusions}

The investigation demonstrated the following:

- Similar tooth shades (A1, B1, and C1) when duplicated by different labs exhibited highly significant color variations.

- According to $\Delta \mathrm{E}$ calculations for each tested shade (A1, B1, and C1), significant variations were observed in shade duplication.

To avoid or limit the variations in shade matching, standardization methods should be considered, such as similar approaches for shade selection, and digital technology, rather than manual shade selection, should be used to reduce the human errors. Similarly, processing parameters including types of porcelain, fabrication technique, and firing cycles should be standardized. All the laboratory technical staff should be trained following the same curriculum and techniques for similarity in shade reproduction.

Author Contributions: Conceptualization, A.S.A. and S.R.H.; methodology, A.S.A., S.R.H., A.S.K., M.Q.J., U.A.B. and M.S.Z.; software, S.R.H. and M.S.Z.; validation, A.S.A., S.R.H. and M.S.Z.; formal analysis, S.R.H.; investigation, A.S.K. and S.R.H.; resources, A.S.A. and S.R.H.; writing-original draft preparation, A.S.A., S.R.H., A.S.K., M.Q.J., U.A.B. and M.S.Z.; writing-review and editing, A.S.A., S.R.H., A.S.K. and M.S.Z.; supervision, S.R.H.; project administration, A.S.A. and S.R.H.; funding acquisition, A.S.A. All authors have read and agreed to the published version of the manuscript.

Funding: This research received no external funding.

Institutional Review Board Statement: Not applicable.

Informed Consent Statement: Not applicable.

Data Availability Statement: Data is available on request from corresponding author. 
Acknowledgments: The research project was approved and supported by the College of Dentistry Research Center (Registration number FR 0607) and Deanship of Scientific Research, King Saud University, Riyadh, KSA.

Conflicts of Interest: The authors declare no conflict of interest.

\section{References}

1. Douglas, R.D.; Brewer, J.D. Variability of porcelain color reproduction by commercial laboratories. J. Prosthet. Dent. 2003, 90, 339-346. [CrossRef]

2. Özdemir, H.; Duymus, Z.Y. The effect of laboratory procedures and repeated-glazing on color of metal-ceramic restoration. Contemp. Clin. Dent. 2019, 10, 239. [PubMed]

3. Rosenstiel, S.F.; Land, M.F. (Eds.) Contemporary Fixed Prosthodontics; Elsevier Health Sciences: St. Louis, MO, USA, 2015.

4. Bin-Shuwaish, M.; Al Fawaz, Y.F.; Al Gamaiah, H.A.; Al Sani, A.S.; Abobakr, I.B.; Alzahrani, K.M.; Almutairi, B.; Attar, E.A.; Vohra, F.; Abduljabbar, T. Technical Accuracy of Dental Laboratories in the Quality and Shade Matching of Porcelain Fused to Metal Crowns: An In Vitro Study. Int. J. Environ. Res. Public Health 2021, 18, 2722. [CrossRef] [PubMed]

5. $\mathrm{Xu}, \mathrm{B}$. Effects of dentin and enamel porcelain layer thickness on the color of various ceramic restorations. J. Esthet. Restor. Dent. 2021, 33, 1051-1058. [CrossRef]

6. Oancea, L.U.; Petre, A.; Burlibasa, M.; Totu, E.E.; Cristache, C.M. Variability in colour reproduction of metal-ceramic crowns. Rev. Chim. 2018, 10, 2655-2661. [CrossRef]

7. Sam, P.; Suresh, V.; Ganapathy, D. Evaluation of variation in shade in metal-ceramic restoration from the shade tab. Drug Invent. Today 2019, 11, 2100-2103.

8. Prabu, P.S.; Prabu, N.M.; Kumar, M.; Abhirami, M. Shade variance in ceramic restoration and shade tab: An in vitro study. J. Pharm. Bioallied Sci. 2012, 4 (Suppl. 2), S139. [CrossRef]

9. Greţa, D.C.; Gasparik, C.; Colosi, H.A.; Dudea, D. Color matching of full ceramic versus metal-ceramic crowns-a spectrophotometric study. Med. Pharm. Rep. 2020, 93, 89. [CrossRef]

10. Carrabba, M.; Vichi, A.; Tozzi, G.; Louca, C.; Ferrari, M. Cement opacity and color as influencing factors on the final shade of metal-free ceramic restorations. J. Esthet. Restor. Dent. 2020. [CrossRef]

11. Rutkauskaite, G.; Baltrušaitytè, A. Spectrophotometrical CIELab color space analysis of CAD-CAM dental ceramics optical properties changes before and after thermocycling. EJMT 2020, 4, 29.

12. Moussa, R. Dental Shade Matching: Recent Technologies and Future Smart Applications. J. Dent. Health Oral Res. 2021, 2, 1-10. [CrossRef]

13. Kalantari, M.H.; Ghoraishian, S.A.; Mohaghegh, M. Evaluation of accuracy of shade selection using two spectrophotometer systems: Vita Easyshade and Degudent Shadepilot. Eur. J. Dent. 2017, 11, 196-200. [CrossRef] [PubMed]

14. Smitha, A.J.; Savitha, P.N. Shade matching in aesthetic dentistry-from past to recent advances. J. Dent. Oral Care Med. 2017, 3, 102.

15. Alqahtani, F. In-vitro efficacy of two spectrophotometer-based shade matching systems for color matching of ceramics after artificial accelerated aging. Braz. Dent. Sci. 2021, 24, 1-7. [CrossRef]

16. Limbu, I.K.; Basnet, B.B. An In-Vitro Study on the Influence of Ceramic Thickness in the Color of Titanium Ceramic Restoration. J. Coll. Med. Sci.-Nepal. 2019, 15, 34-39. [CrossRef]

17. Omar, H.; Atta, O.; El-Mowafy, O. Difference between selected and obtained shade for metal-ceramic crown systems. Oper. Dent. 2008, 33, 502-507. [CrossRef]

18. Grah, C.L.; O’Brien, W.J.; Boenke, K.M. Differences in color between fired porcelain and shade guides. Int. J. Prosthodont. 1992, $5,510-514$.

19. Chitumalla, R.; Al Jarrah, A.K.; Munaga, S.; Shrivastava, D.; Ali, A.S.; Singhi, A. To Evaluate and Compare the Effect of Number of Firings on the Color Stability of All-Ceramic System Using a Spectrophotometer: An in Vitro Study. Ann. Rom. Soc. Cell Biol. 2021, 25, 1209-1217.

20. Finch, K.; Jarad, F.D.; Adeyemi, A.A.; Al-Shamaa, S. An audit of shade reproduction of fixed metal ceramic prostheses. Eur. J. Prosthodont. Restor. Dent. 2011, 19, 94-98.

21. Alnasser, H.A.; Elhejazi, A.A.; Al-Abdulaziz, A.A.; Alajlan, S.S.; Habib, S.R. Effect of Conventional and Electronic Cigarettes Smoking on the Color Stability and Translucency of Tooth Colored Restorative Materials: An In Vitro Analysis. Coatings 2021, 11, 1568. [CrossRef]

22. Swapna, B.; Shalini, K.; Sreeramulu, B. Effect of Repeated Firings on the Color of Porcelain: An In Vitro Study. Indian J. Dent. Adv. 2018, 10, 21-29.

23. Vladislavic, N.Z.; Tadin, A.; Gavic, L.; Jerkovic, D.; Franic, I.; Verzak, Z. In vivo evaluation of whitening toothpaste efficiency and patient treatment satisfaction: A randomized controlled trial. Clin. Oral Investig. 2022, 26, 739-750. [CrossRef] [PubMed] 